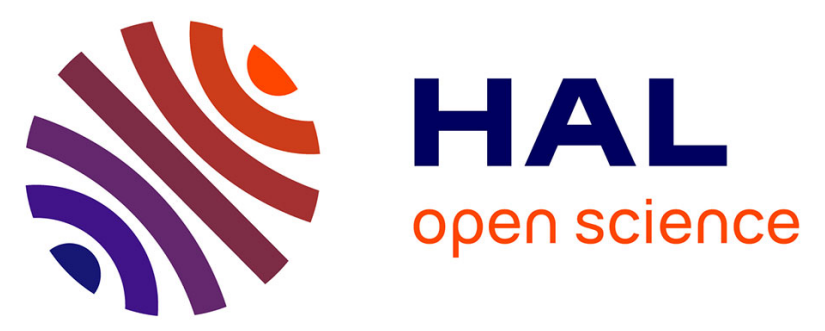

\title{
Rapid increase in dispersal during range expansion in the invasive ladybird Harmonia axyridis
}

Eric Lombaert, Arnaud Estoup, Benoit Facon, B. Joubard, J. C. Gregoire, A. Jannin, Aurelie Blin, Thomas T. Guillemaud

\section{- To cite this version:}

Eric Lombaert, Arnaud Estoup, Benoit Facon, B. Joubard, J. C. Gregoire, et al.. Rapid increase in dispersal during range expansion in the invasive ladybird Harmonia axyridis. Journal of Evolutionary Biology, 2014, 27 (3), pp.508-517. 10.1111/jeb.12316 . hal-02637907

\section{HAL Id: hal-02637907 https: / hal.inrae.fr/hal-02637907}

Submitted on 15 Sep 2020

HAL is a multi-disciplinary open access archive for the deposit and dissemination of scientific research documents, whether they are published or not. The documents may come from teaching and research institutions in France or abroad, or from public or private research centers.
L'archive ouverte pluridisciplinaire HAL, est destinée au dépôt et à la diffusion de documents scientifiques de niveau recherche, publiés ou non, émanant des établissements d'enseignement et de recherche français ou étrangers, des laboratoires publics ou privés. 


\title{
Rapid increase in dispersal during range expansion in the invasive ladybird Harmonia axyridis
}

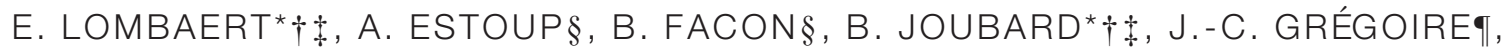 \\ A. JANNINף, A. BLIN* $+\div \&$ T. GUILLEMAUD* $\dagger+$ \\ *UMR 1355 ISA, Inra, Sophia-Antipolis, France \\ $\dagger$ †UMR ISA, Université de Nice Sophia Antipolis, Sophia-Antipolis, France \\ $\$ U M R 7254$ ISA, CNRS, Sophia-Antipolis, France \\ $\S U M R$ CBGP (INRA/IRD/CIRAD/Montpellier SupAgro), Inra, Montferrier-sur-Lez, France \\ qLUBIES laboratory, Université Libre de Bruxelles, Brussels, Belgium
}

\section{Keywords:}

biological invasion;

expansion front;

flight speed;

harlequin ladybird;

spatial sorting.

\begin{abstract}
The evolutionary trajectories associated with demographic, genetic and spa tial disequilibrium have become an issue of growing interest in population biology. Invasive species provide unique opportunities to explore the impact of recent range expansion on life history traits, making it possible to test for a spatial arrangement of dispersal abilities along the expanding range, in particular. We carried out controlled experiments in laboratory conditions to test the hypothesis of an increase in dispersal capacity with range expansion in Harmonia axyridis, a ladybird that has been invading Europe since 2001. We found a marked increase in the flight speed of the insects from the core to the front of the invasion range in two independent sampling transects. By contrast, we found that two other traits associated with dispersal (endur ance and motivation to fly off) did not follow the same spatial gradient. Our results provide a striking illustration of the way in which predictable direc tional genetic changes may occur rapidly for some traits associated with dis persal during biological invasions. We discuss the consequences of our results for invasion dynamics and the evolutionary outcomes of spatially expanding populations.
\end{abstract}

\section{Introduction}

Some invasive species have detrimental impacts on human health, economy or environment (Ruiz et al., 2000; Pimentel et al., 2001; Olden et al., 2004), whereas others are regarded as beneficial organisms because they act as a source of food or help to regulate other damaging invasive species (Guillemaud et al., 2011). Regardless, studies of all these organisms provide useful information about fundamental issues in ecology and evolutionary biology (e.g. Lodge, 1993; Huey et al., 2005). The course of a biological invasion can be divided into three steps (Elton, 1958): (i) the introduction of a

Correspondence: Eric Lombaert, UMR 1301 IBSV (INRA / Université de Nice Sophia Antipolis / CNRS), INRA, 400 Route des Chappes, BP 167 06903 Sophia Antipolis Cedex, France.

Tel.: +334923865 06; fax: +33492386401;

e-mail: lombaert@sophia.inra.fr group of individuals into a remote area, (ii) their estab lishment and (iii) their spatial expansion into the new area. Each of these steps provides us with an opportu nity to test theoretical predictions. In particular, spatial expansion can be used to explore the eco evolutionary processes at work in populations in 'spatial disequilib rium' (sensu Phillips et al., 2010), in which space plays a crucial role in shaping demographic, genetic and life history trait patterns.

How do we expect genetic variation to be spatially distributed in a newly expanding population? We know that expanding populations are confronted by evolu tionary forces, which vary spatially from the core to the front of the expansion. Genetic drift, for example, is thought to be an important factor during spatial expan sion: at the front, fewer individuals are responsible for recurrent founder events, resulting in potentially large effects on genetic structure in this zone through the random loss of alleles, the stochastic variation of allele 
frequencies and spatial differentiation (Excoffier et al., 2009). Various selective factors may also act during expansion, leading to spatially differential adaptation. One of these factors is population density, which may vary considerably along the expansion gradient, being high at the core of the expanding population and low at its edges. Consequently, density dependent traits may evolve in opposite ways in different parts of the geographical range (Phillips, 2009; Phillips et al., 2010; Kelehear et al., 2012; Kilkenny \& Galloway, 2013). Finally, dispersal capacity is probably heteroge neous over space, simply because the best dispersers are likely to be the first to found new populations and are therefore likely to be at the vanguard of the expanding front (Van Valen, 1971). Heritable traits associated with dispersal would therefore be expected to display deterministic sorting with range expansion (Shine et al., 2011). The combination of this mecha nism and the spatial heterogeneity of selective pressures may have major evolutionary consequences, modifying the overall frequencies of these traits in the population.

Higher levels of dispersal at the edge of a spatially growing population have been predicted by a number of recently developed theoretical models, with and without the assumption of a variation of selective pres sures with density and/or space (Travis \& Dytham, 2002; Hughes et al., 2007; Phillips et al., 2008; Travis et al., 2009, 2010; Burton et al., 2010; Shine et al., 2011; Benichou et al., 2012). By analysing proxies of dispersal abilities, this prediction has been confirmed in a number of species displaying range expansion around their native areas in response to climate change (e.g. Cwynar \& Macdonald, 1987; Hill et al., 1999; Thomas et al., 2001; Simmons \& Thomas, 2004; Darling et al., 2008; Leotard et al., 2009), but in only a few intro duced invasive species (but see Phillips et al., 2006; Monty \& Mahy, 2010; Berthouly Salazar et al., 2012). Invasions constitute natural situations in which this question can be addressed appropriately for several rea sons: (i) in some cases, a precise recent history of intro duction and spread is available; (ii) many invasions are still underway, resulting in a maintenance of the spatial disequilibrium and (iii) progressive changes to the envi ronment (e.g. climate change) are not a prerequisite (Hill et al., 2011). Moreover, the question of the evolu tion of dispersal capacity in invasive populations is highly relevant, because it may accelerate spread, with serious applied and theoretical consequences (Travis $\delta$ Dytham, 2002; Phillips et al., 2007, 2010; Travis et al., 2009; Benichou et al., 2012; Lehe et al., 2012). Two obstacles may hinder the emergence of a spatial gradi ent of dispersal traits with range expansion: (i) founder events during introduction may greatly decrease the genetic variability of the traits associated with dispersal and (ii) introduction may have occurred too recently for the observation of measurable changes in the spa tial distribution of genetic variation. However, recent studies have indicated that strong genetic bottlenecks are less frequent than previously thought in successful invasive populations (Bossdorf et al., 2005; Wares et al., 2005; Dlugosch \& Parker, 2008), and rapid evolutionary changes have repeatedly been observed in invasive spe cies (e.g. Huey et al., 2005; Whitney \& Gabler, 2008).

In this study, we investigated the spatial variation of dispersal abilities during the spread of the harlequin ladybird Harmonia axyridis in Europe. This insect species of Asian origin combines a number of characteristics making it a good model for testing the prediction that dispersal levels are higher at the edge of the range of an introduced population that is expanding spatially. First, its worldwide invasion is very well documented (Lombaert et al., 2010, 2011; Brown et al., 2011). In par ticular, H. axyridis was first observed in 2001 in Belgium (Adriaens et al., 2003), and its spread in Eur ope has been well monitored ever since (Brown et al., 2011). Second, this species is known to have passed through only moderate bottlenecks during its introduc tion into Europe (Lombaert et al., 2010; Facon et al., 2011). Indeed, the genetic diversity of the European invasive population is almost as broad as that of the native populations. This high degree of genetic diversity can be explained at least partly by an admixture event between a wild eastern North American invasive popu lation and a laboratory strain formerly used for biocon trol purposes in Europe (Lombaert et al., 2010, 2011; Turgeon et al., 2011). Third, heritable variation for dis persal capacity is known to exist in $H$. axyridis: differen tial flight capacities have been selected independently in the laboratory on at least two occasions: once in a native population (Seko et al., 2008) and once in a European biocontrol strain (Tourniaire et al., 2000).

We characterized the spatial variation of $H$. axyridis dispersal abilities during the expansion of its range in Europe. We collected ladybirds from eight sites, along two transects, extending from the core of the popu lation to two different edges of the invaded area in Eur ope. We then used selectively neutral genetic markers (microsatellites) to check that all the insects were derived from the expansion of the same population unit. Finally, we studied three traits associated with flight, which is known to be the major process involved in dispersal of ladybirds (Hodek \& Honek, 1996; Brown et al., 2011), in controlled laboratory experiments: fly ing speed, flying endurance and motivation to fly off.

\section{Materials and methods}

\section{Sampling and rearing}

The invasion of Europe by $H$. axyridis probably began in 2001, as indicated by the first records of feral popula tions near Ghent and Brussels in Belgium, followed by a rapid demographic and spatial expansion over much of Europe (Adriaens et al., 2008; Brown et al., 2011). 
We thus considered the centre of Belgium to be the invasion core. Data on the spatial and temporal pro gress of the invasion front in France (date of first obser vation in each French administrative area (département)) were obtained from the French national $H$. axyridis sur vey (Fig. 1, Ternois, 2010). Based on our knowledge of the expansion history of $H$. axyridis, we collected, between October and November 2010, eight $H$. axyridis population samples along two transects (four samples per transect) extending from the core region of the European invasion (Brussels area) to the invasion fronts in Southern and Western France (Table S1, Fig. 1). All population samples consisted of at least 90 live adult individuals collected from an area of less than $10 \mathrm{~km}^{2}$. Each population sample was characterized by (i) the transect to which it belonged (transect ID), (ii) its latitude, (iii) the geographical distance, in kilome tres, to the core sample, measured with Google Earth V4.3 (Google, 2008) and (iv) the date on which the species was first observed at the sampling site con cerned (Ternois, 2010) (Table S1, Fig. 1). As expected, these last two variables were highly correlated (Pearson's correlation coefficient $\left.0.95 ; P<10^{-4}\right)$. In subsequent

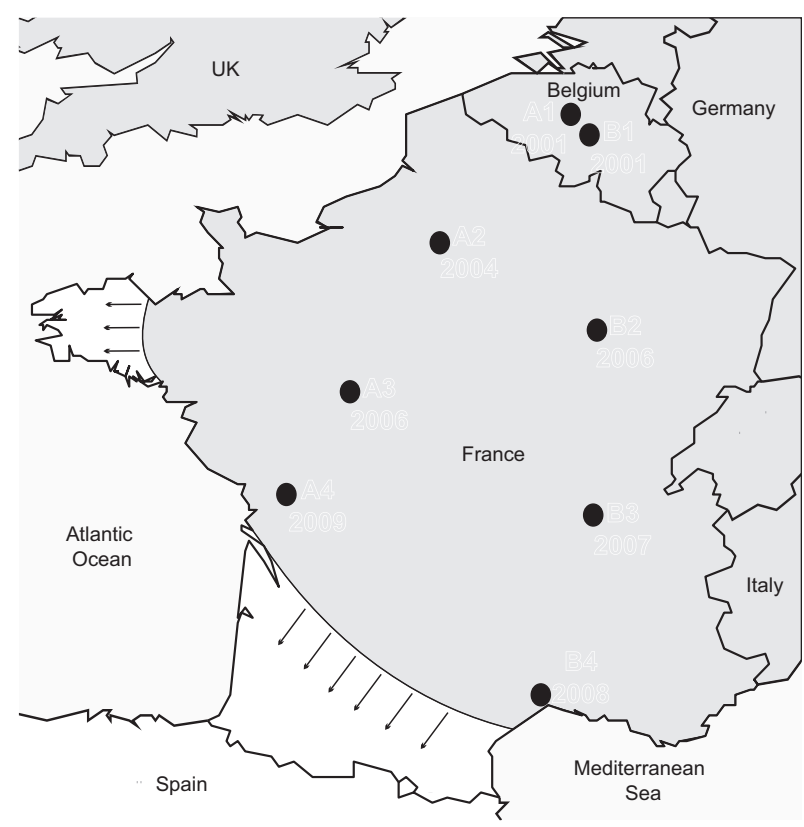

Fig. 1 Geographical origins of the Harmonia axyridis samples collected along two transects in Western Europe. The core area of the invasive outbreak is located in Belgium. The grey area roughly corresponds to the distribution of the species in 2010. Arrows indicate the direction of expansion. Each black spot corresponds to a population sample. Letters (A or B) indicate the transect, and the associated numbers give the sample codes (see Table S1). The years indicated below the sample codes are the dates on which the species was first observed at the geographical site concerned (see Table S1). statistical analyses, we decided to use the date of the first observation to account for the distance to the core, because it was less sensitive to environmental variation (which may artificially slow down or accelerate spread) than geographical distance in kilometres.

Before beginning the controlled laboratory experi ments, we reared all eight population samples collected in natura $\left(G_{0}\right)$ in the laboratory for two generations $\left(G_{1}\right.$ and $G_{2}$ ), under strictly controlled conditions, to mini mize biases due to maternal and environmental effects (but see Braendle et al., 2006). During these two gener ations, individuals were fed exclusively on ionized Ephestia kuehniella (Lepidoptera: Pyralidae) eggs and reared in constant environmental conditions $\left(23^{\circ} \mathrm{C}\right.$; 50\% HR; L : D 16:8). For each population, $G_{1}$ was initiated from $90 \mathrm{G}_{0}$ individuals (45 males and 45 females) and $G_{2}$ was initiated from $100 G_{1}$ individuals (50 males and 50 females). The rearing protocol design is described in Fig. S1. Generation $\mathrm{G}_{2}$ contained a large number of individuals (more than 1600 individuals per population), and males and females were separated immediately after emergence to prevent mating, which is not a prerequisite for dispersal in this species (Brown et al., 2011). G individuals were then maintained in the same environmental conditions for 2 weeks, to ensure that they were sexually mature at the start of the experiment.

\section{Genetic differentiation between populations}

Many studies have suggested that multiple introduc tions of invasive species might be a common phenome non (Bossdorf et al., 2005; Estoup \& Guillemaud, 2010). We therefore began by checking that the eight popula tion samples used in this study were part of the same spatial expansion of a single invasive outbreak. We genotyped $31 \mathrm{G}_{0}$ individuals from each of the eight population samples at 18 microsatellite loci, as described by Loiseau et al. (2009). The degree of genetic differentiation between population samples was assessed by calculating pairwise $F_{\mathrm{ST}}$ estimates (Weir $\&$ Cockerham, 1984). Fisher's exact tests, based on con tingency tables of genotypic frequencies, were also car ried out for all pairs of populations, with Genepop software (Raymond \& Rousset, 1995; Rousset, 2008). Finally, we used the Bayesian clustering approach implemented in STRUCTURE v2.3.3 (Pritchard et al., 2000) to infer the number of population units within the area studied (see Fig. S2 for a description of the analysis).

\section{Flight speed and endurance experiment}

We used an automated flight mill system (Movie S1), which made it possible to assess the flying speed and endurance of 10 individuals simultaneously. Each of the ten mills was isolated in a box and consisted of a 
horizontal steel rod bent by $90^{\circ}$ at both ends: the first end was inserted into the hollow needle of a vertical syringe head, which served as a rotation axis. The second end was used as the attachment point for the insect. The horizontal part of the steel rod was $15.915 \mathrm{~cm}$ long. Thus, when an insect completed one complete rotation, it was considered to have covered a distance of $1 \mathrm{~m}$. An infrared ray emitted by a photogate was interrupted by a flag attached to the middle of the steel rod. This photogate was connected to a computer, which recorded the time co ordinates for each rotation. The whole flight mill system was located in a chamber maintained at $23{ }^{\circ} \mathrm{C}$, with controlled lighting and air movement.

Before each trial, ladybirds were isolated and starved for one hour. Body weight, sex and elytral colour pat terns (hereafter referred to as 'morphs', corresponding to four of the five classes proposed by Seo et al., 2008) were also recorded. For each mill, a ladybird randomly chosen from the eight population samples and the two sexes was fixed, by the pronotum, to the attachment point. Recording began as soon as the insect began to fly, which was generally immediately, and lasted for one hour. In total, 752 individuals were tested (see Table S2), corresponding to a mean of 47 replicates per population and per sex (minimum 45; maxi mum 49).

We analysed the following response variables: (i) the total distance travelled over the entire $60 \mathrm{~min}$ (referred to hereafter as 'flight speed') and (ii) the $\left[2 * D_{30} / D_{60}\right]$ ratio (hereafter referred to as 'endurance'), where $D_{30}$ is the distance travelled during the first $30 \mathrm{~min}$ and $D_{60}$ is the total flight mill distance. For both response vari ables, we used mixed general linear models ('Imer' function from the 'Ime4' $\mathrm{R}$ package) with the following factors included as fixed effects: the date of first obser vation and the latitude of each collected sample, the day of the experiment (day 1 is the first day of the experiment, which lasted 17 days, this variable being highly correlated with the age of the ladybirds), body weight, sex and transect ID (A or B, Fig. 1). Three fac tors were also included as random effects: flight mill ID number (10 levels), morph (four levels) and population sample (eight levels) acting on the transect fixed effect. We used the Akaike information criterion (AIC) to select the best model, with the following model com parison procedure (Zuur et al., 2009). We first selected the best random effect structure, by comparing models with different random effects but with the same fixed structure (referred to hereafter as the full fixed struc ture), which included all simple fixed effects and simple interactions between the date of first observation and either sex or transect. Once the best random effect structure had been identified (lowest AIC value), we compared all models with various degrees of complexity of the fixed effect structure but the same random effect structure. We thus compared the full range of models, extending from a model with no fixed effects to the full fixed structure, and we retained the model with the lowest AIC.

\section{Experiment assessing the motivation to fly off}

We assessed the motivation of $H$. axyridis individuals to fly off, by a method similar to that described by Li et al. (2010). The flight stands consisted of an inverted white plastic funnel (h: $180 \mathrm{~mm}$, dia.: $110 \mathrm{~mm}$ at base). The base of the funnel was surrounded by water, to prevent the individuals from walking off the stand. An indivi dual that had been isolated and starved in a $2 \mathrm{~mL}$ opaque microtube for $36 \mathrm{~h}$ was installed on the base of the funnel. The experiment began with the opening of the tube. The occurrence of flight and the time from the tube being opened to take off were then recorded with Observer 5.0 software (Noldus Information Tech nology, Wageningen, The Netherlands). The trial ended when the adults flew off the stand or when $300 \mathrm{~s}$ had elapsed. Four individuals were tested in parallel during a single trial, with a space of $10 \mathrm{~cm}$ between adjacent funnels. Individuals were chosen randomly from the eight population samples, but all the insects in any given trial were of the same sex, to prevent mating pheromone interactions. The sex and morph of the insects tested were recorded. The experiment took place in a growth chamber maintained at $23.5^{\circ} \mathrm{C}$, with con trolled lighting and air movement. Temperature and humidity were recorded at the start of each trial. In total, we tested 760 individuals, corresponding to a mean of 47.5 replicates per population and per sex (minimum 45; maximum 48).

The following response variables were considered: (i) take off behaviour (the proportion of 'flyers') and (ii) the time from release of the individual (opening of the tube) to take off (referred to hereafter as 'take off time'). We analysed the proportion of flyers with mixed generalized linear models with a binomial probability distribution and a logit link function (the 'lmer' func tion from the 'Ime4' $\mathrm{R}$ package). For the take off time variable, we used a Cox's proportional hazards model for survival data with random effects (the 'coxph' func tion in the $\mathrm{R}$ 'survival' package). For both response variables, we considered the following factors as fixed effects: the date of first observation, the latitude of each sample collected, the day of the experiment (day 1 is the first day of the experiment, which lasted 12 days, this variable being strongly correlated with the age of the ladybirds), the isolation time (i.e. the time spent by each individual in the microtube before the trial), sex and transect ID (A or B). Three factors were also included as random effects: funnel ID number, morph and population sample (eight levels), nested within transect. The best model was selected as that with the smallest AIC, according to the procedure described in the flight mill experiment section. All statistical 
analyses were performed with $\mathrm{R}$ software V2.13.0 (R Development Core Team, 2011).

\section{Results}

\section{Genetic differentiation between populations}

Pairwise $F_{\mathrm{ST}}$ estimates were low, with a mean value of -0.001 and no value exceeding 0.007 . None of the 28 exact tests of genotypic differentiation gave a significant $P$ value at the 5\% threshold (smallest $P$ value 0.058 ), even without correction for multiple comparisons. STRUCTURE clustering analysis provided consistent results over the 20 runs tested for each $K$ value. The mean natural logarithm of the likelihood of the data $(\ln \mathrm{P}(\mathrm{X} \mid K))$ was maximal for $K \quad$ l. Mean $\ln \mathrm{P}(\mathrm{X} \mid K)$ decreased (the $\Delta \mathrm{K}$ method was thus not applicable, Evanno et al., 2005), and its variance increased with increasing values of $K$ (Fig. S2). In addition, individual $Q$ values for $K \quad 2$ revealed that all individuals were similarly admixed (coefficient of variation of $Q \quad 7.6 \%$ ), as expected when no genetic structure is supported by the data (Pritchard et al., 2003). Overall, the microsatel lite data provide strong evidence that all the samples were derived from the expansion of a single population unit.

\section{Flight speed and endurance}

For the response variable 'flight speed', the final model included the date of first observation, latitude, day of the experiment, body weight, sex, transect, sex $\mathrm{x}$ date of first observation and transect $x$ date of first observa tion interactions as fixed effects and mill ID number as a random effect. The statistical results obtained with this model are reported in Table 1. A highly significant fixed effect was found for the date of first observation $\left(P<10^{-3}\right)$. Flight speed was higher for individuals collected from sites with more recent first observation dates (i.e. closer to the front) (Fig. 2). Mean flight speed increased from about 2500 to 2800 metres per hour from the core to the front. The only other signifi cant fixed effect was the day of the experiment $\left(P<10^{-3}\right)$ : beetles travelled further in the last few days of the experiment than in the first few days. This prob ably reflects differences in the ages of the ladybirds, which were all born at about the same time (the maxi mum age difference between the oldest and youngest insects was 4 days). Randomization within our experi mental design (Fig. S3) ensures us an absence of corre lation between both significant fixed effects, date of first observation and day of the experiment (Pearson correlation coefficient $0.035, P \quad 0.333)$. Body weight was not significant at the $5 \%$ threshold $(P$ 0.055), but a slight trend towards highest flight speed in the largest ladybirds was observed (mean weight of lady birds per population sample can be found in Table S2). None of the other variables or interactions included in the model selected were significant: $\operatorname{sex}(P \quad 0.225)$ and transect $(P \quad 0.824)$ had no significant effect, as well as latitude $\left(\begin{array}{ll}P & 0.072\end{array}\right)$ despite a strong correlation (Pearson correlation coefficient $-0.912, \quad P<10^{-3}$ ) with the highly significant date of first observation vari able (see above).

For the response variable 'flight endurance', the best model, with the lowest AIC criterion, included no fixed effect and the variable 'mill' as a random effect, indicat ing that endurance was similar between samples. The overall mean value of endurance ratio was greater than one (1.16), indicating that ladybirds covered greater distances during the first half of the flight (first $30 \mathrm{~min}$ ) than during the second half of the flight.

The response variables of the two Belgian popula tion samples corresponding to the core of the two transects did not differ significantly, and analyses in which the two core populations were inversed (each
Table 1 Results obtained with the best model selected from the various linear mixed models run for the trait 'flight speed

\begin{tabular}{|c|c|c|c|c|c|}
\hline & Total fligh & hill distance & & & \\
\hline \multicolumn{6}{|l|}{ Parameter } \\
\hline Fixed effect & Estimate & Std error & $t$ value (df $\quad 735$ ) & & $P$ \\
\hline Date of first observation & 93.01 & 26.91 & 3.457 & & $<10^{-3}$ \\
\hline Latitude & 65.10 & 36.08 & 1.804 & & 0.072 \\
\hline Day of the experiment & 42.35 & 5.40 & 7.843 & & $<10^{-3}$ \\
\hline Body weight & 10.55 & 5.48 & 1.923 & & 0.055 \\
\hline Sex & 123.53 & 131.46 & 0.940 & & 0.348 \\
\hline Transect & 144.07 & 113.34 & 1.271 & & 0.204 \\
\hline $\begin{array}{l}\text { Sex } \times \text { date of first } \\
\text { observation }\end{array}$ & -22.54 & 18.57 & -1.213 & & 0.225 \\
\hline $\begin{array}{l}\text { Transect } \times \text { date of } \\
\text { first observation }\end{array}$ & -4.65 & 21.15 & -0.220 & & 0.826 \\
\hline $\begin{array}{l}\text { Random effect } \\
\text { Mill }\end{array}$ & & & $\begin{array}{l}-2 \text { Log likelihood ratio (df } \\
5.476\end{array}$ & 1) & $\begin{array}{l}P \\
0.019\end{array}$ \\
\hline
\end{tabular}


used in the other transect) gave similar results (results not shown).

\section{Motivation to fly off}

For both studied response variables, that is, the propor tion of flyers and take off time, the final selected model included funnel ID number as a random effect, and transect and isolation time as fixed effects (Table 2). Thus, for these two response variables, the date of first observation had no significant effect. We found a signif icant $\left(P<10^{-3}\right)$ effect of isolation time on both the proportion of flyers and take off time, with the motiva tion to fly off being greater for longer isolation times. In both bases, the transect effect was significant
$(P<0.05)$, with a larger propensity to fly in transect $\mathrm{B}$ (e.g. $P_{F L Y}$ transectA 0.45 and $P_{F L Y}$ transectB 0.53$)$. Despite the absence of significant differences between the two Belgian population samples, the inversion of these two samples eliminated the transect effect for both response variables (results not shown).

\section{Discussion}

Considerable interest has recently focused on the evo lution of nonequilibrium populations as a result of spa tial spread during range expansion (e.g. Excoffier $\delta$ Ray, 2008; Excoffier et al., 2009; Sexton et al., 2009; Phillips et al., 2010; Hill et al., 2011; Shine et al., 2011). Changes in range margin due to modern day climate

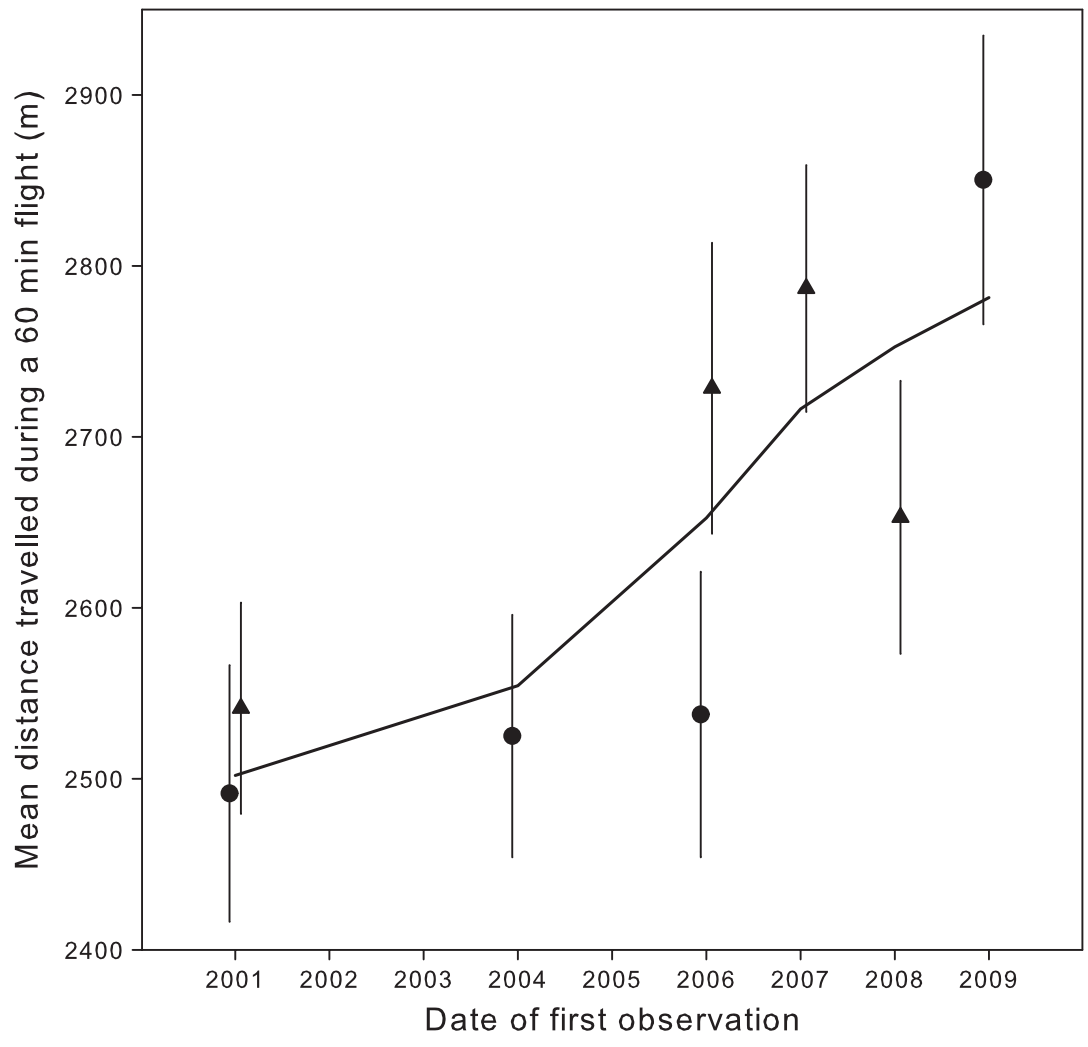

Fig. 2 Mean distance travelled in $1 \mathrm{~h}$ by Harmonia axyridis in flight mills, as a function of dates of first observation of the species during range expansion. Triangles and circles indicate mean population values for transects A and B, respectively. The vertical bars are standard errors. The line corresponds to the mean values predicted by the selected statistical model (see Table 1).

Table 2 Results obtained with the best model selected from the various statistical models run for the traits assessing the motivation to fly off (i.e. proportion of flyers and time to take off).

\begin{tabular}{|c|c|c|c|c|c|c|c|c|c|}
\hline \multirow[b]{3}{*}{ Fixed effects } & \multicolumn{4}{|c|}{ Proportion of flyers } & \multicolumn{5}{|c|}{ Time to take off } \\
\hline & \multicolumn{4}{|c|}{ Selected random effect funnel } & \multicolumn{5}{|c|}{ Selected random effect funnel } \\
\hline & Estimate & Std error & $\begin{array}{l}\text { z value } \\
\text { (df 739) }\end{array}$ & $P$ & Estimate & Std error & $\mathrm{Chi}^{2}$ & & $P$ \\
\hline Isolation time & 0.005 & 0.001 & 3.323 & $<10^{-3}$ & 0.004 & 0.001 & 12.66 (df & 1) & $<10^{-3}$ \\
\hline
\end{tabular}


change and the current explosion in the number of bio logical invasions have led to many recent studies on this topic (Phillips et al., 2010; Hill et al., 2011). It has been predicted that dispersal capacity is greater at the edge of expanding populations than at their core (Travis \& Dytham, 2002; Phillips et al., 2010; Shine et al., 2011). We tested this hypothesis for a well known invasive insect, through controlled laboratory experi ments and the use of an appropriate sampling design.

\section{Evidence for the evolution of flying speed}

We found clear evidence of a strong, rapid increase in flight speed with range expansion of $H$. axyridis in Wes tern Europe. We found that individuals with grandpar ents sampled close to the front covered larger distances $(\sim+10 \%)$ during a one hour trial in a flight mill than individuals with grandparents sampled close to the core of the invasion. The front populations used here were first observed in 2008 and 2009, depending on the transect, whereas the core population samples were first observed in 2001. The cline of dispersal capacity observed in this study was thus remarkably rapid, as it occurred in less than a decade (i.e. in less than 20 gen erations, assuming two generations per year, Koch, 2003). Population genetic structure analyses confirmed that all samples originated from the expansion of a sin gle population unit. The observed variation of dispersal ability over space is, therefore, not due to several spa tially independent introductions of genetically differen tiated groups of $H$. axyridis ladybirds. Instead, it likely corresponds to the post introduction organization of genetic variation within a single geographically contin uous population. The absence of a significant effect of transect variable (alone or in interaction) suggests that the observed spatial gradient for flight speed was repro ducible over space and was therefore unlikely to have occurred by chance, through genetic drift or mutation surfing (Hallatschek et al., 2007). Finally, the absence of a significant effect of latitude suggests that the observed spatial gradients were not due to adaptation to a geoclimatic cline.

By contrast, we detected no spatial variation of flight endurance and, therefore, no trade off between flight speed and endurance in $H$. axyridis, although such a trade off might be expected (e.g. Wilson \& James, 2004; Stephens \& Wiens, 2008; Oufiero et al., 2011). Longer flight mill trials may be required to detect differ ences in endurance between insects from the core and front populations of this invasive species. However, although not significant, the observed trend towards greater endurance at the front than in the core is not consistent with a trade off.

We also observed no significant variation in motiva tion to fly off over the expansion range. However, the moderate effect of transect does suggest that variations in motivation to fly off may have a genetic basis, which would make it possible for evolutionary responses to occur. Unlike flight speed, the motivation to fly off is a complex behavioural trait that may be subject to sev eral different selection pressures associated with resource foraging, mating and escaping from predators. The effect of the spatial sorting of dispersal may thus be attenuated by these complex patterns of selective pressure in traits of this type.

\section{Evolutionary consequences of the spatial sorting of dispersal traits}

The spatial sorting of genetically controlled traits under lying dispersal abilities over the expansion range is likely to have important evolutionary consequences. For example, a rare allele or a new mutation that can surf on the expansion wave, reaching high frequencies in newly colonized areas (Edmonds et al., 2004; Klopfstein et al., 2006; Excoffier \& Ray, 2008; Hallatschek \& Nelson, 2008; Lehe et al., 2012), will end up being associated with the more dispersive genotypes of the population (Travis et al., 2010). Moreover, the spatial variation of selective pressures in expanding populations is likely to lead to the negative or positive selection of genotypes with strong dispersal abilities at the level of the overall population (Phillips et al., 2010). For example, Allee effects may constitute a disadvan tage for the good migrants, due to the low population densities encountered at the invasion front (e.g. Travis \& Dytham, 2002). However, this issue may not be par ticularly important in $H$. axyridis, as it has recently been shown that inbreeding depression (one of the mecha nisms underlying Allee effects, Courchamp et al., 1999) has been purged from invasive populations of this spe cies, including the European population (Facon et al., 2011). On the other hand, selection for dispersal is pos sible, as in the case of classical negative density depen dence: low levels of intraspecific competition at the invasion front result in higher growth rates (e.g. Travis \& Dytham, 2002; Burton et al., 2010), conferring a selective advantage on the best dispersers.

Further studies are required to determine the impor tance of the observed spatial sorting of flight speed over the expansion of the range of $H$. axyridis in the evolu tion of this species and its current invasion of Europe. Indeed, it is not possible to conclude definitively from our results that there has been selection for the flight speed of $H$. axyridis during expansion in Europe, as the spatial cline observed here may result solely from the spatial rearrangement of individuals according to their dispersal capacity (Shine et al., 2011). This issue could be resolved by analysing the overall dispersal polymor phism of the population over time, to assess potential changes to genetically determined dispersal trait fre quencies. However, based on current knowledge of the biology of $H$. axyridis, including its highly generalist nature in food and habitat use (Koch, 2003; Brown 
et al., 2011), and the purging of deleterious mutations during invasion (Facon et al., 2011), we suggest that the benefits of being in a new environment with lower intraspecific competition are likely to outweigh the costs in this species. This has not yet been demon strated unequivocally for $H$. axyridis, but the rapid spread of invasive $H$. axyridis populations over various continents suggests that this is probably the case (Brown et al., 2011).

\section{Conclusion and perspectives}

Harmonia axyridis can now be found on almost all conti nents (Africa, South America, North America, Europe, Brown et al., 2011). The expansion of the range of this species in continents other than Europe may provide more robust, independent, experimental replicates for confirming and extending our results. However, we should first properly explore the heritability of dispersal abilities, which is highly suggested but not formally demonstrated in our experiment. In general, it would be interesting to explore the genomic basis of the observed trait variation, to improve our understanding of the genetic and selective mechanisms at work and to facilitate explorations of the fate of dispersal polymor phism during the entire worldwide invasion process.

This study is one of the first to provide strong evi dence for rapid spatial sorting of a trait directly associ ated with dispersal with spatial expansion of the range of an invading species. The observed shift towards a higher flying speed at the invasion front of European $H$. axyridis populations was remarkably rapid, as it was demonstrated after only 8 years of expansion, corre sponding to about 16 generations (Koch, 2003), high lighting a rather high rate of evolution $(\sim 0.07$ haldanes, Haldane, 1949; Hendry \& Kinnison, 1999; Gingerich, 2001), even in the case of invasive species (Prentis et al., 2008; Whitney \& Gabler, 2008). These results have important implications at both applied and fundamental levels. We expect there to be a rapid acceleration in the rate of spread of this harmful species (Travis \& Dytham, 2002; Phillips et al., 2007), and a rapid evolution of life history traits positively and nega tively linked to dispersal. Future studies on invasive species, including $H$. axyridis, should consider the evo lution of other important traits, such as competitiveness and rates of reproduction and cannibalism during spa tial expansion (Phillips et al., 2010; Rudolf et al., 2010). Information about the evolution of these additional key life history traits, together with findings for dispersal, would provide useful insight into the dynamics of invasive species.

\section{Acknowledgments}

We wish to thank Adrien Adelsri, Violaine Chatre Belle, Samuel Courtaut, Bertrand Gauffre, Louis
Hautier, Sylvain Lanziliere, Guillaume Laugier, Bernard Lemesle and Ashraf Tayeh for providing us with live Harmonia axyridis samples. We also thank Xavier Fau vergue for helping us with data summarizing and mu eros for friendly support in Brussels. This work was funded by grants from the French ANR Biodiversité \#ANR 06 BDIV 00801 and the French Agropolis Fon dation (RTRA, Montpellier, BIOFIS project \#1001 001).

\section{References}

Adriaens, T., Branquart, E. \& Maes, D. 2003. The Multicol oured Asian Ladybird Harmonia axyridis Pallas (Coleoptera: Coccinellidae), a threat for native aphid predators in Belgium? Belgian J. Zool. 133: 195196.

Adriaens, T., San Martin y Gomez, G. \& Maes, D. 2008. Invasion history, habitat preferences and phenology of the invasive ladybird Harmonia axyridis in Belgium. Biocontrol 53: 6988.

Benichou, O., Calvez, V., Meunier, N. \& Voituriez, R. 2012. Front acceleration by dynamic selection in Fisher population waves. Phys. Rev. E 86: 5.

Berthouly Salazar, C., van Rensburg, B.J., Le Roux, J.J., van Vuuren, B.J. \& Hui, C. 2012. Spatial sorting drives morpho logical variation in the invasive bird, Acridotheris tristis. PLoS ONE 7: e38145.

Bossdorf, O., Auge, H., Lafuma, L., Rogers, W.E., Siemann, E. \& Prati, D. 2005. Phenotypic and genetic differentiation between native and introduced plant populations. Oecologia 144: 111 .

Braendle, C., Davis, G.K., Brisson, J.A. \& Stern, D.L. 2006. Wing dimorphism in aphids. Heredity 97: 192199.

Brown, P., Thomas, C., Lombaert, E., Jeffries, D., Estoup, A. \& Lawson Handley, L. J. 2011. The global spread of Harmonia axyridis (Coleoptera: Coccinellidae): distribution, dispersal and routes of invasion. Biocontrol 56: 623641 .

Burton, O.J., Phillips, B.L. \& Travis, J.M.J. 2010. Trade offs and the evolution of life histories during range expansion. Ecol. Lett. 13: 12101220.

Courchamp, F., Clutton Brock, T. \& Grenfell, B. 1999. Inverse density dependence and the Allee effect. Trends Ecol. Evol. 14: 405410.

Cwynar, L.C. \& Macdonald, G.M. 1987. Geographical Variation of Lodgepole Pine in Relation to Population History. Am. Nat. 129: 463469.

Darling, E., Samis, K.E. \& Eckert, C.G. 2008. Increased seed dispersal potential towards geographic range limits in a Paci fic coast dune plant. New Phytol. 178: 424435.

Dlugosch, K.M. \& Parker, I.M. 2008. Founding events in spe cies invasions: genetic variation, adaptive evolution, and the role of multiple introductions. Mol. Ecol. 17: 431449.

Edmonds, C.A., Lillie, A.S. \& Cavalli Sforza, L.L. 2004. Muta tions arising in the wave front of an expanding population. Proc. Natl. Acad. Sci. USA 101: 975979.

Elton, C.S. 1958. The Ecology of Invasions by Animals and Plants. Methuen \& Co LTD, London.

Estoup, A. \& Guillemaud, T. 2010. Reconstructing routes of invasion using genetic data: why, how and so what? Mol. Ecol. 19: 41134130.

Evanno, G., Regnaut, S. \& Goudet, J. 2005. Detecting the number of clusters of individuals using the software STRUC TURE: a simulation study. Mol. Ecol. 14: 26112620. 
Excoffier, L. \& Ray, N. 2008. Surfing during population expan sions promotes genetic revolutions and structuration. Trends Ecol. Evol. 23: 347351.

Excoffier, L., Foll, M. \& Petit, R.J. 2009. Genetic consequences of range expansions. Annu. Rev. Ecol. Evol. Syst. 40: 481501.

Facon, B., Hufbauer, R.A., Tayeh, A., Loiseau, A., Lombaert, E., Vitalis, R. et al. 2011. Inbreeding depression is purged in the invasive insect Harmonia axyridis. Curr. Biol. 21: 424427.

Gingerich, P.D. 2001. Rates of evolution on the time scale of the evolutionary process. Genetica 112: 127144.

Google 2008. Google Earth (Version 4.3.7284.3916).

Guillemaud, T., Ciosi, M., Lombaert, E. \& Estoup, A. 2011. Biological invasions in agricultural settings: insights from evolutionary biology and population genetics. C.R. Biol. 334 237246.

Haldane, J.B.S. 1949. Suggestions as to quantitative measure ment of rates of evolution. Evolution 3: 5156.

Hallatschek, O. \& Nelson, D.R. 2008. Gene surfing in expand ing populations. Theor. Popul. Biol. 73: 158170

Hallatschek, O., Hersen, P., Ramanathan, S. \& Nelson, D.R. 2007. Genetic drift at expanding frontiers promotes gene segregation. Proc. Natl. Acad. Sci. USA 104: 1992619930.

Hendry, A.P. \& Kinnison, M.T. 1999. Perspective: the pace of modern life: measuring rates of contemporary microevolu tion. Evolution 53: 16371653.

Hill, J.K., Thomas, C.D. \& Blakeley, D.S. 1999. Evolution of flight morphology in a butterfly that has recently expanded its geographic range. Oecologia 121: 165170.

Hill, J.K., Griffiths, H.M. \& Thomas, C.D. 2011. Climate change and evolutionary adaptations at species' range margins. Annu. Rev. Entomol. 56: 143159.

Hodek, I. \& Honek, A. 1996. Ecology of Coccinellidae. Kluwer Academic Publishers, Dordrecht/Boston/London.

Huey, R.B., Gilchrist, G.W. \& Hendry, A.P. 2005. Using inva sive species to study evolution. In: Species Invasions: Insights Into Ecology, Evolution and Biogeography (D.F. Sax, J.J. Stac howicz \& S.D. Gaines, eds), pp. 140 164. Sinauer Associates Inc, Sunderland, MA, USA.

Hughes, C.L., Dytham, C. \& Hill, J.K. 2007. Modelling and analysing evolution of dispersal in populations at expanding range boundaries. Ecol. Entomol. 32: 437445.

Kelehear, C., Brown, G.P. \& Shine, R. 2012. Rapid evolution of parasite life history traits on an expanding range edge. Ecol. Lett. 15: 329337.

Kilkenny, F.F. \& Galloway, L.F. 2013. Adaptive divergence at the margin of an invaded range. Evolution 67: 722731 .

Klopfstein, S., Currat, M. \& Excoffier, L. 2006. The fate of mutations surfing on the wave of a range expansion. Mol. Biol. Evol. 23: 482490.

Koch, R.L. 2003. The multicolored Asian lady beetle, Harmonia axyridis: a review of its biology, uses in biological control, and non target impacts. J. Insect Sci. 3: 116.

Lehe, R., Hallatschek, O. \& Peliti, L. 2012. The rate of benefi cial mutations surfing on the wave of a range expansion. PLoS Comput. Biol. 8: el 002447.

Leotard, G., Debout, G., Dalecky, A., Guillot, S., Gaume, L., McKey, D. et al. 2009. Range expansion drives dispersal evo lution in an equatorial three species symbiosis. PLOS ONE 4: e5377.

Li, H., Toepfer, S. \& Kuhlmann, U. 2010. Flight and crawl ing activities of Diabrotica virgifera virgifera (Coleoptera:
Chrysomelidae) in relation to morphometric traits. J. Appl. Entomol. 134: 449461.

Lodge, D.M. 1993. Biological invasions lessons for ecology. Trends Ecol. Evol. 8: 133137.

Loiseau, A., Malausa, T., Lombaert, E., Martin, J.F. \& Estoup, A. 2009. Isolation and characterization of microsatellites in the harlequin ladybird, Harmonia axyridis (Coleoptera, Cocci nellidae), and cross species amplification within the family Coccinellidae. Mol. Ecol. Resour. 9: 934937.

Lombaert, E., Guillemaud, T., Cornuet, J.M., Malausa, T., Facon, B. \& Estoup, A. 2010. Bridgehead effect in the world wide invasion of the biocontrol harlequin ladybird. PLoS ONE 5: e9743.

Lombaert, E., Guillemaud, T., Thomas, C.E., Lawson Handley, L.J., Li, J., Wang, S. et al. 2011. Inferring the origin of popu lations introduced from a genetically structured native range by approximate Bayesian computation: case study of the invasive ladybird Harmonia axyridis. Mol. Ecol. 20: 46544670.

Monty, A. \& Mahy, G. 2010. Evolution of dispersal traits along an invasion route in the wind dispersed Senecio inaequidens (Asteraceae). Oikos 119: 15631570.

Olden, J.D., LeRoy Poff, N., Douglas, M.R., Douglas, M.E. \& Fausch, K.D. 2004. Ecological and evolutionary consequences of biotic homogenization. Trends Ecol. Evol. 19: 1824.

Oufiero, C.E., Walsh, M.R., Reznick, D.N. \& Garland, T. Jr 2011. Swimming performance trade offs across a gradient in community composition in Trinidadian killifish (Rivulus hart ii). Ecology 92: 170179.

Phillips, B.L. 2009. The evolution of growth rates on an expanding range edge. Biol. Lett. 5: 802804 .

Phillips, B.L., Brown, G.P., Webb, J.K. \& Shine, R. 2006. Inva sion and the evolution of speed in toads. Nature 439: 803 .

Phillips, B.L., Brown, G.P., Greenlees, M., Webb, J.K. \& Shine, R. 2007. Rapid expansion of the cane toad (Bufo marinus) invasion front in tropical Australia. Austral Ecol. 32: 169176.

Phillips, B.L., Brown, G.P., Travis, J.M.J. \& Shine, R. 2008. Reid's paradox revisited: the evolution of dispersal kernels during range expansion. Am. Nat. 172: S34 S48.

Phillips, B.L., Brown, G.P. \& Shine, R. 2010. Life history evo lution in range shifting populations. Ecology 91: 16171627.

Pimentel, D., McNair, S., Janecka, J., Wightman, J., Simmonds, C., O'Connell, C. et al. 2001. Economic and environmental threats of alien plant, animal, and microbe invasions. Agric. Ecosyst. Environ. 84: 120.

Prentis, P.J., Wilson, J.R.U., Dormontt, E.E., Richardson, D.M. \& Lowe, A.J. 2008. Adaptive evolution in invasive species. Trends Plant Sci. 13: 288294.

Pritchard, J.K., Stephens, M. \& Donnelly, P. 2000. Inference of population structure using multilocus genotype data. Genetics 155: 945959.

Pritchard, J.K., Wen, W. \& Falush, D. 2003. Documentation for structure software: Version 2. http://pritch.bsd.uchicago. edu.

R Development Core Team 2011. R: A Language and Environ ment for Statistical Computing. R Foundation for Statistical Computing, Vienna, Austria.

Raymond, M. \& Rousset, F. 1995. Genepop (version. 1.2), a population genetics software for exact tests and ecumeni cism. J. Hered. 86: 248249.

Rousset, F. 2008. GENEPOP '007: a complete re implementa tion of the GENEPOP software for Windows and Linux. Mol. Ecol. Resour. 8: 103106. 
Rudolf, V.H.W., Kamo, M. \& Boots, M. 2010. Cannibals in space: the coevolution of cannibalism and dispersal in spa tially structured populations. Am. Nat. 175: 513524.

Ruiz, G.M., Rawlings, T.K., Dobbs, F.C., Drake, L.A., Mullady, T., Huq, A. et al. 2000. Global spread of microorganisms by ships Ballast water discharged from vessels harbours a cocktail of potential pathogens. Nature 408: 4950.

Seko, T., Yamashita, K. I. \& Miura, K. 2008. Residence period of a flightless strain of the ladybird beetle Harmonia axyridis Pallas (Coleoptera: Coccinellidae) in open fields. Biol. Control 47: 194198.

Seo, M.J., Kim, G.H. \& Youn, Y.N. 2008. Differences in biolog ical and behavioural characteristics of Harmonia axyridis (Coleoptera: Coccinellidae) according to colour patterns of elytra. J. Appl. Entomol. 132: 239247.

Sexton, J.P., McIntyre, P.J., Angert, A.L. \& Rice, K.J. 2009. Evolution and ecology of species range limits. Annu. Rev. Ecol. Evol. Syst. 40: 415436.

Shine, R., Brown, G.P. \& Phillips, B.L. 2011. An evolutionary process that assembles phenotypes through space rather than through time. Proc. Natl. Acad. Sci. USA 108: 57085711.

Simmons, A.D. $\&$ Thomas, C.D. 2004. Changes in dispersal during species' range expansions. Am. Nat. 164: 378395.

Stephens, P.R. \& Wiens, J.J. 2008. Testing for evolutionary tra de offs in a phylogenetic context: ecological diversification and evolution of locomotor performance in emydid turtles. J. Evol. Biol. 21: 7787.

Ternois, V.E.C. 2010. Observatoire permanent pour le suivi de la Coccinelle asiatique Harmonia axyridis (Pallas, 1773) en France. http://vinc.ternois.pagesperso orange.fr/cote nature/ Harmonia axyridis/.

Thomas, C.D., Bodsworth, E.J., Wilson, R.J., Simmons, A.D., Davies, Z.G., Musche, M. et al. 2001. Ecological and evolu tionary processes at expanding range margins. Nature 411: 577581.

Tourniaire, R., Ferran, A., Giuge, L., Piotte, C. \& Gambier, J. 2000. A natural flightless mutation in the ladybird, Harmo nia axyridis. Entomol. Exp. Appl. 96: 3338.

Travis, J.M.J. \& Dytham, C. 2002. Dispersal evolution during invasions. Evol. Ecol. Res. 4: 11191129.

Travis, J.M.J., Mustin, K., Benton, T.G. \& Dytham, C. 2009. Accelerating invasion rates result from the evolution of density dependent dispersal. J. Theor. Biol. 259: 151158.

Travis, J.M.J., Munkemuller, T. \& Burton, O.J. 2010. Mutation surfing and the evolution of dispersal during range expansions. J. Evol. Biol. 23: 26562667.

Turgeon, J., Tayeh, A., Facon, B., Lombaert, E., De Clercq, P., Berkvens, N. et al. 2011. Experimental evidence for the phenotypic impact of admixture between wild and biocon trol Asian ladybird (Harmonia axyridis) involved in the Euro pean invasion. J. Evol. Biol. 24: 10441052.

Van Valen, L. 1971. Group selection and the evolution of dis persal. Evolution 25: 591598.

Wares, J.P., Hughes, A.R. \& R.K., G. 2005. Mechanisms that drives evolutionary change: insights from species introduc tions and invasions. In: Species Invasions: Insights Into Ecology, Evolution and Biogeography (D.F. Sax, J.J. Stachowicz \& S.D. Gaines, eds), pp. 229 257. Sinauer Associates Inc, Sunderland, MA, USA.

Weir, B.S. \& Cockerham, C. 1984. Estimating $F$ statistics for the analysis of population structure. Evolution 38: 13581370 .

Whitney, K.D. \& Gabler, C.A. 2008. Rapid evolution in intro duced species, 'invasive traits' and recipient communities: challenges for predicting invasive potential. Divers. Distrib. 14: 569580 .

Wilson, R.S. \& James, R.S. 2004. Constraints on muscular per formance: trade offs between power output and fatigue resistance. Proc. Biol. Sci. 271: S222 S225.

Zuur, A.F., Ieno, E.N., Walker, N.J., Saveliev, A.A. \& Smith, G.M. 2009. Mixed Effects Models and Extensions in Ecology With $R$. Springer, New York.

\section{Supporting information}

Additional Supporting Information may be found in the online version of this article:

Figure $\mathbf{S} 1$ Rearing protocol design.

Figure S2 Likelihood of the multilocus genetic data as a function of the number of genetic clusters among European samples of Harmonia axyridis.

Figure S3 Number of ladybirds used every day during the flight mill experiment.

Table S1 European Harmonia axyridis samples col lected between October and November 2010 along two transects extending from the outbreak core to zones close to the invasion front (see Fig. 1).

Table S2 Number (n) and mean weight in milligrams (with standard deviation) of male and female ladybirds tested in the flight speed and endurance experiment.

Movie S1 The flight mill system.

Data deposited at Dryad: doi:10.5061/dryad.v1s3s 